\title{
A rhamnose-binding lectin from sea bass (Dicentrarchus labrax) plasma agglutinates and opsonizes pathogenic bacteria
}

\author{
Matteo Cammarata ${ }^{\mathrm{a}, *}$, Maria Giovanna Parisi ${ }^{\mathrm{a}}$, Gigliola Benenati ${ }^{\mathrm{a}}$, Gerardo R. Vasta ${ }^{\mathrm{b}}$, Nicolò Parrinello ${ }^{\mathrm{a}}$ \\ ${ }^{a}$ Department of Biological, Chemical, Pharmaceutical Science and Technology, Marine Immunobiology Laboratory, University of Palermo, Via Archirafi 18, Palermo, Italy

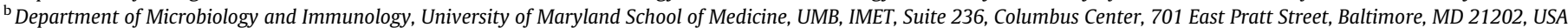

\section{A R T I C L E I N F O}

\section{Article history:}

Received 11 December 2013

Revised 19 January 2014

Accepted 20 January 2014

Available online 28 January 2014

\section{Keywords:}

Rhamnose binding lectin

Dicentrarchus labrax

Teleost

Opsonin

Hemagglutinins

Bacteria

\begin{abstract}
A B S T R A C T
The discovery of rhamnose-binding lectins (RBLs) in teleost fish eggs led to the identification of a novel lectin family characterized by a unique sequence motif and a structural fold, and initially proposed to modulate fertilization. Further studies of the RBL tissue localization and gene organization were also suggestive of role(s) in innate immunity. Here we describe the purification, and biochemical and functional characterization of a novel RBL (DIRBL) from sea bass (Dicentrarchus labrax) serum. The purified DIRBL had electrophoretic mobilities corresponding to $24 \mathrm{kDa}$ and $100 \mathrm{kDa}$ under reducing and non-reducing conditions, respectively, suggesting that in plasma the DIRBL is present as a physiological homotetramer. DIRBL subunit transcripts revealed an open reading frame encoding 212 amino acid residues that included two tandemly-arrayed carbohydrate-recognition domains, and an 18-residue signal sequence at the N-terminus. The deduced size of $24.1 \mathrm{kDa}$ for the mature protein was in good agreement with the subunit size of the isolated lectin. Binding activity of DIRBL for rabbit erythrocytes could be inhibited in the presence of rhamnose or galactose, did not require calcium, and was optimal at around $20^{\circ} \mathrm{C}$ and within the $\mathrm{pH}$ 6.5-8.0 range. DIRBL agglutinated Gram positive and Gram negative bacteria, and exposure of formalin-killed Escherichia coli to DIRBL enhanced their phagocytosis by D. labrax peritoneal macrophages relative to the unexposed controls. Taken together, the results suggest that plasma DIRBL may play a role in immune recognition of microbial pathogens and facilitate their clearance by phagocytosis.
\end{abstract}

(c) 2014 Elsevier Ltd. All rights reserved.

\section{Introduction}

Lectins are carbohydrate-binding proteins widely distributed in eukaryotic taxa, and are involved in multiple biological processes, such as development and immune responses (Vasta et al., 1994; Arason, 1996; Kaltner and Stierstorfer, 1998; Kilpatrick, 2002). With regards to the latter, lectins can bind to microbial surface glycans through their CRDs (carbohydrate recognition domains), and based on their multivalent oligomeric organization and the presence of additional effector domains, not only recognize microbial pathogens but also mediate effector functions including agglutination, opsonization, and complement activation, that result in their immobilization, phagocytosis, killing and removal from the internal milieu (Gabius, 1997; Kilpatrick, 2002; Loris, 2002; Vasta et al., 2004; Turner, 1996; Sharon and Lis 2004; Fujita et al., 2004). On the basis of conserved amino acid sequence motifs in their CRDs, structural folds, and calcium requirements lectins have been classified into various families that include among others, the C-type, F-type, and rhamnose-binding lectins (RBLs), galectins and

\footnotetext{
* Corresponding author. Tel.: +39 091 23891805; fax: +39 09123860855.

E-mail address: matteo.cammarata@unipa.it (M. Cammarata).
}

pentraxins (Turner, 1996; Sharon and Lis 2004; Arason 1996; Vasta et al., 2004; reviewed in Vasta and Ahmed, 2008, and Vasta et al., 2011).

Lectin repertoires in teleost fish are highly diversified (Vasta et al., 2011, 2012), and include not only representatives of the lectin families described in mammals, but also members of lectin families initially identified and characterized in fish species, such as F-type lectins (Odom and Vasta, 2006; Bianchet et al., 2010) and RBLs (Tateno et al., 1998; Jimbo et al., 2007; Terada et al., 2007).

RBLs are $\mathrm{Ca}^{2+}$-independent lectins with specificity for rhamnose and galactosides, particularly abundant in teleosts and ascidians, and other aquatic invertebrate species, such as annelids, bivalves, and echinoderms (Ogawa et al., 2011). The sea urchin (Anthocidaris crassispina) egg dimeric lectin (SUEL) was first isolated as a D-galactoside-binding lectin and later shown to preferentially bind L-rhamnose. This is consistent with the same orientation of the hydroxyl groups at C2 and C4 in the pyranose rings of both L-rhamnose and D-galactose. The 100 amino acids-long CRD displays conserved sequence motifs, such as YGR, DPC and KYL (Terada et al., 2007), and houses eight highly conserved cysteine residues engaged in four disulfide bridges with characteristic 
topology that determine a unique structural fold (Jimbo et al., 2007; Terada et al., 2007).

In teleost fish, most of the RBLs described to date have been isolated from the egg cortex (Tateno et al., 1998; Lam and $\mathrm{Ng} 2002$; Shiina et al., 2002; Tateno et al., 2002a,b; Jimbo et al., 2007; Terada et al., 2007; Watanabe et al., 2008). Because rhamnose is absent in animal cells but widely distributed in the bacterial cell wall, the ability of trout egg RBLs to recognize and bind lipopolysaccharide and lipoteichoic acid, and agglutinate both Gram-positive and Gram-negative bacteria suggested a role in egg defense against infectious challenge (Tateno et al., 2002a). The presence of RBLs in skin mucus also supported their proposed function(s) in immune defense, and further work showed their participation in multiple antimicrobial activities such as inhibition of proliferation, cytotoxicity, and opsonization of non-self cells or particles (Hosono et al., 1993; Lam and Ng 2002; Tateno et al., 2002a; Terada et al., 2007). A putative natural ligand of fish RBL was identified as globotriasylceramide (Gb3), a glycosphingolipid that is abundant in membrane lipid rafts (Watanabe et al., 2009; Ogawa et al., 2011).

In this study we report the purification, cloning, and structural and functional characterization of an RBL present in plasma of the sea bass Dicentrarchus labrax. The protein had been observed as a secondary product in the purification of an F-type lectin (DIFBL) from sea bass plasma that we reported elsewhere (Salerno et al., 2009). The purified sea bass RBL (DIRBL) showed a tetrameric structure in which each single subunit contains two tandemlyarrayed, distinct CRDs that exhibit the sequence motif typical of the teleost RBLs. Agglutinating activity for E. coli and Vibrio alginolitycus, and their opsonization for sea bass macrophages suggest that it may function in recognition of potential microbial pathogens in the blood stream.

\section{Material and methods}

\subsection{Chemicals and molecular biology reagents}

Unless otherwise specified, chemicals and molecular biology reagents were from Sigma-Aldrich (USA), at the highest purity available.

\subsection{Animals, collection of blood and tissue samples, and preparation of} tissue extracts

Sea bass ( $D$. labrax) ( $n=25$; approximately $250 \mathrm{~g}$ each) were provided by the Ittica Trappeto fish farm (Trappeto, Palermo, Italy). Animals were anesthetized in seawater containing 0.02\% 3-aminobenzoic acid ethyl ester (MS-222 Sigma), and bled by heart puncture. The blood was allowed to clot at room temperature for $1 \mathrm{~h}$, the serum separated by centrifugation at $800 \mathrm{~g}\left(10 \mathrm{~min}, 4^{\circ} \mathrm{C}\right)$, aliquoted, and stored at $-20^{\circ} \mathrm{C}$ until use.

\subsection{Purification of DIRBL}

The DIRBL was isolated from sea bass serum by an optimized two-step chromatography procedure (Table 1), following Cammarata et al. (2007). The first step consisted of affinity chromatography on fucose-agarose, with $0.2 \mathrm{M}$ fucose elution. As monitored by absorbance at $280 \mathrm{~nm}$, the elution profile yielded two peaks, the second of which displayed the highest hemagglutinating activity (titer: 256-512) and contained the DIFBL (Salerno et al., 2009). To purify DIRBL, the pooled fractions of the first peak $(20 \mathrm{ml})$ were loaded onto a galactose-agarose column (Pierce). The column was washed with $1.0 \mathrm{M} \mathrm{NaCl}$, followed by TBS (10 volumes) at a $0.2 \mathrm{ml} /$ min flow rate, and the DIRBL eluted with $20 \mathrm{ml}$ of $50 \mathrm{mM}$ galactose in TBS at the same flow rate, monitored by absorbance at $280 \mathrm{~nm}$, and $2 \mathrm{ml}$ fractions collected. The eluted fractions were tested for their hemagglutinating activity towards rabbit erythrocytes, and those that exhibited the highest activity were pooled and analyzed by SDS-PAGE electrophoresis.

\subsection{Hemagglutination assay}

Rabbit and sheep erythrocytes (RBC; supplied by Istituto Zooprofilattico della Sicilia) were washed three times with PBS, centrifuged at $500 \mathrm{~g}$ for $10 \mathrm{~min}$ at $4{ }^{\circ} \mathrm{C}$ and suspended at $1 \%$ in TBS containing $0.1 \%(\mathrm{w} / \mathrm{v})$ pig gelatin. A volume $(25 \mu \mathrm{l})$ of sea bass serum $(1: 10)$ or $25 \mu \mathrm{l}$ of the purified DIRBL preparation $(250 \mu \mathrm{g} / \mathrm{ml})$ dialyzed in TBS were serially (2-fold) diluted with TBS-gelatin in 96-well round-bottom microtiter plates (Nunc, Denmark), and mixed with an equal volume of RBC suspension. The hemagglutinating titer (HT) was measured after a $1 \mathrm{~h}$ incubation at $37^{\circ} \mathrm{C}$ and expressed as the reciprocal of the highest dilution showing clear agglutination.

\subsection{Protein content estimation}

Protein content was estimated according to the method of Bradford (1976)using bovine serum albumin (BSA) as a standard.

\subsection{Polyacrylamide gel electrophoresis}

SDS-PAGE (10\%) was carried out following the method of Laemmli (1970) under reducing conditions (5\% mercaptoethanol). To assess the apparent molecular size of DIRBL, the polyacrylamide gels were calibrated with low range standard proteins (Bio-Rad, Richmond, CA). Proteins were stained with Coomassie brillant Blue R250.

\subsection{N-terminal sequencing}

The purified lectin from SDS-PAGE gels run under reducing conditions was electrophoretically transferred ( $4 \mu \mathrm{g} /$ well) to Immobilon polyvinylidene difluoride membrane (Millipore, Bedford, MA, USA), at $160 \mathrm{~mA}$ for $1 \mathrm{~h}$. The membrane was stained with an aqueous solution of Coomassie Blue R-250, extensively rinsed with distilled water, and the band corresponding to the isolated protein was excised and applied to a protein sequencer (Procise, PerkinElmer, Switzerland). The sequence was determined by automated Edman degradation using a protein sequencer at the Institute of Protein Biochemistry (CNR Naples).

\subsection{Phylogenetic analysis}

The DIRBL protein sequence identified in a D. labrax EST library as Rhamnose binding protein (Appendix 3, Contig_1715; Sarropoulou et al., 2009) was aligned with RBLs sequences from several species [(Channa argus (gi|189096288|gb|ACD76075.1); Lutjanus sanguineus (gi|322423476|gb|ADX01347.1); Tetraodon nigroviridis (gi|47222797|emb|CAG01764.1); Oncorhynchus mykiss STL2 (gi|185134480|ref|NP_001117668.1|); Ciona intestinalis (gi|198412427|ref|XP_002131218.1|); Nematostella vectensis (gi|156358465|ref|XP_001624539.1| predicted protein); Strongylocentrotus purpuratus SAL (gi|72110389|ref|XP_788214.1|)] and a phylogenetic tree was constructed by the Neighbor-Joining method (NJ) after 1000 bootstrap iterations by using CLC workbench 6.4. Calculations of theoretical protein characteristics from the deduced peptide sequence were performed with ProtParam (www.expasy.ch) and signal peptide cleavage site have been predicted by the SignalP algorithm. The putative tertiary structure of each CRD from DIFBL was developed with SWISS-MODEL and the Swiss-PdbViewer (Guex and Peitsch, 1997; Arnold et al., 2006; 
Schwede et al., 2003) by using of the RBL CSL3 structure as the template (Protein Data Bank accession code $2 \mathrm{z} \times 2 \mathrm{~A} ; 1.80 \AA$ ).

\subsection{Carbohydrate specificity}

The carbohydrate specificity of DIRBL was assessed by inhibition of its agglutinating activity for rabbit RBC by saccharides. Inhibition experiments were carried out using decreasing concentrations (starting from $100 \mathrm{mM}$, in TBS pH 7.4; $5 \mathrm{mM} \mathrm{CaCl}_{2} ; \mathrm{pH} 7.4$ ) of monosaccharides (L-fucose, L-rhamnose, D-galactose, D-glucose, D-mannose, N-Acetyl-galactosamine, and N-Acetyl-glucosamine), oligosaccharides (maltose, lactose, lactulose), and mannan (from Saccharomyces cerevisae).

\subsection{Physical and chemical treatments}

To examine the divalent cation requirements for lectin binding, either $\mathrm{CaCl}_{2}$ or $\mathrm{MgCl}_{2}$ was added to the $\mathrm{HA}$ medium to reach a $5-10 \mathrm{mM}$ final concentration. EDTA $(10 \mathrm{mM})$ or EGTA $(10 \mathrm{mM})$ was used to examine the effect of $\mathrm{Ca}^{2+} / \mathrm{Mg}^{2+}$ depletion on the lectin activity. To examine the thermal stability of the protein, the purified lectin $(250 \mu \mathrm{g} / \mathrm{ml})$ was incubated at $18^{\circ} \mathrm{C}, 37^{\circ} \mathrm{C}, 50^{\circ} \mathrm{C}, 60^{\circ} \mathrm{C}$, $70{ }^{\circ} \mathrm{C}$ and $90^{\circ} \mathrm{C}$ for $20 \mathrm{~min}$ and cooled down for $10 \mathrm{~min}$ on ice before the HA. Susceptibility of the lectin to freeze-thaw was examined by carrying out the $\mathrm{HA}$ on samples maintained at $-20^{\circ} \mathrm{C}$ for 2 months and thawed at room temperature. The $\mathrm{pH}$ dependence of the DIRBL agglutinating activity was examined by Sorensen phosphate buffer (SPB; $0.15 \mathrm{M} \mathrm{KH}_{2} \mathrm{PO}_{4}, 0.15 \mathrm{M} \mathrm{Na}_{2} \mathrm{HPO}_{4}$ ) with $\mathrm{pH}$ values ranging from 3 to 11 by addition of either acetic acid (down to $\mathrm{pH} 3$ ) or sodium carbonate (up to $\mathrm{pH} 11$ ). The lectin solution $(250 \mu \mathrm{g} / \mathrm{ml})$ was incubated the various buffer solutions in a microtiter plate for $30 \mathrm{~min}$ before the HA assay.

\subsection{Bacterial suspensions and agglutination}

Bacteria (Escherichia coli; Aeromonas hidrophyla, Staphylococcus aureus and $V$. alginolyticus) (Table 3 ) were grown to log phase in tryptic soy broth (TSB) containing $3 \% \mathrm{NaCl}$ at $25^{\circ} \mathrm{C}$, with continuous shaking $(120 \mathrm{rpm})$ in a Gallenkamp incubator. Cell numbers were estimated by absorbance at $600 \mathrm{~nm}$, as previously correlated to plate counts. Bacteria were fixed by adding formaldehyde to the bacterial stock suspension to a $2 \%$ final concentration, and the mixture shaken $(120 \mathrm{rpm})$ overnight at $21^{\circ} \mathrm{C}$. After centrifugation at $6000 \mathrm{~g}$ for $15 \mathrm{~min}\left(4^{\circ} \mathrm{C}\right)$, the formalin-killed bacteria were washed three times with sterile PBS, suspended in PBS containing $0.1 \%(\mathrm{w} / \mathrm{v})$ gelatin to obtain $1 \times 10^{9}$ cells $/ \mathrm{ml}$, and stored at $4{ }^{\circ} \mathrm{C}$ until use.

\subsection{Opsonic activity for peritoneal macrophages}

For the phagocytosis assay, the formalin-killed bacteria $E$. coli were washed three times with sterile PBS, suspended $1 \times 10^{9} / \mathrm{ml}$ in carbonate buffer $\left(0.1 \mathrm{M} \mathrm{Na}_{2} \mathrm{CO}_{3}, 0.1 \mathrm{M} \mathrm{NaHCO}_{3}, \mathrm{pH} 9.5\right)$ containing $0.1 \mathrm{mg} / \mathrm{ml} \mathrm{FITC}$ and incubated $30 \mathrm{~min}$ at $37^{\circ} \mathrm{C}$ with gentle shaking. FITC-treated formalin-killed bacteria were washed three times in $\mathrm{NaCl} 0.9 \%$ and twice in PBS containing $2 \mathrm{mM} \mathrm{CaCl}_{2}$ (PBS$\mathrm{Ca})$, and suspended $\left(1 \times 10^{8} / \mathrm{ml}\right)$ in PBS-Ca. FITC-treated formalin-killed bacteria $\left(1 \times 10^{8} / \mathrm{ml}\right)$ were mixed in a microtube with purified F-lectin $(5,10,25 \mu \mathrm{g} / \mathrm{ml})$ in PBS-Ca, incubated at $18^{\circ} \mathrm{C}$ for $60 \mathrm{~min}$, and washed twice with the same buffer. In the controls the purified lectin was replaced with PBS-Ca. The opsonized bacteria $(100 \mu \mathrm{l})$ were incubated with an equal volume of Peritoneal cavity cells (PCC) $\left(1 \times 10^{7} / \mathrm{ml}\right)$ for $30 \mathrm{~min}$ at $18^{\circ} \mathrm{C}$. Fluorescence of the non-phagocytosed bacteria, was quenched by adding trypan blue $(2 \mathrm{mg} / \mathrm{ml})$ in $0.02 \mathrm{M}$ citrate buffer $\mathrm{pH} 4.4$, containing $0.15 \mathrm{M}$ $\mathrm{NaCl}$ and $2 \mathrm{mg} / \mathrm{ml}$ crystal violet in PBS [32]. The phagocytosed fluorescent bacteria were observed under a UV light microscope equipped with Nomarsky differential interference contrast optic (Diaplan, Leica, Wetzlar, Germany). The phagocytic rate (PR) was determined as the percent of cells showing internalized bacteria, and the phagocytic index (PI) as the average of ingested bacteria relative to the total phagocyte number.

\section{Results}

\section{1. labrax RBL purification and characterization}

Fractions from the first peak eluted from the fucose-agarose column revealed hemagglutinating activity $(1: 32-1: 256)$ that could only be inhibited by L-rhamnose or D-galactose, but not by concentrations up to $200 \mathrm{mM}$ of L-fucose, glucose, lactose, GalNAc, GlcNAc or other sugars tested (Table 1). Accordingly, the protein contained in the first peak was further purified by affinity chromatography on a D-galactose-agarose column $(1.6 \times 5 \mathrm{~cm})$, eluted with D-galactose. A typical affinity chromatography purification profile is shown in Fig. 1 . The eluted protein represented approximately $0.1-0.5 \%$ of the total serum protein loaded onto the column. Hemagglutination titers (HT) of the eluted fractions ( $n=28-36,0.3-0.5 \mathrm{mg} / \mathrm{ml}$; Fig. 1) for rabbit RBC ranged from $1: 16$ to $1: 64$, and the activity was completely abolished by a pre-incubation with $4.2 \mathrm{mM}$ L-rhamnose. As shown in Table 2, the DIRBL pool had 60- to 70-fold higher activity (specific activity: 4,267) than that of whole serum. Fractions 6-12 lacked hemagglutinating activity. The L-rhamnose-eluted fractions, examined by SDS-PAGE under non-reducing conditions, revealed a single $102.0 \pm 3.2 \mathrm{kDa}$ component, while under reducing conditions the apparent mass was $24.1 \pm 1.6 \mathrm{kDa}$ (Fig. 2).

\section{2. $N$ terminal sequence of DIRBL}

The selected protein identified by SDS-PAGE under non-reducing conditions was transferred to PVDF membrane and sequenced. The N-terminal sequence was GVPTETVTTCEGNHVHRL.

A GenBank search revealed identities at several amino acid positions with RBL-type lectin family members, and a $100 \%$ of identity was obtained with a complete open reading frame transcript identified in a D. labrax EST library as Rhamnose binding protein (Sarropoulou et al., 2009).

\subsection{DIRBL sequence analysis}

The open reading frame of the DIRBL encoding 221 amino acids (Supplementary Fig. 1). The nucleotide sequence revealed a 71nucleotide $5^{\prime}$-UTR that precedes the putative translation start site. The deduced protein sequence contains a signal peptide at the $\mathrm{N}$ terminal with a cleavage site that resides between $A^{19}$ and $G^{20}$ (Fig. 3A) as predicted by the SignalP algorithm. This sequence contains the already identified 18 amino acid sequence identified at the N-terminal. The calculated molecular mass of the DIRBL was $24.1 \mathrm{kDa}$ (ProtParam; www.expasy.ch), with a theoretical isoelectric point of 5.84 .

A comparative sequence analysis (Supplementary Fig. 1) revealed the presence of two CRDs spanning from $\mathrm{Thr}^{27}$ to Cys ${ }^{118}$ (N-CRD) and from Val ${ }^{125}$ to $\mathrm{Cys}^{214}$ (C-CRD) connected by a six amino acid linker peptide. The Fig. 4A show a multiple alignment of CRD from different species, conservation of the canonical RBL sequence motif is shown by a grey tone gradient; the four cysteine bridges are shown by blue lines; the blue arrows indicate the EYGK residues involved in carbohydrate binding in mouse RBL and present in D. labrax RBL. 
Table 1

Purification steps of DIRBL and DIFBL.

\begin{tabular}{|c|c|c|c|c|c|c|c|}
\hline Purification stage & $\begin{array}{l}\text { Volume } \\
\mathrm{ml}\end{array}$ & $\begin{array}{l}\text { Protein content }(\mathrm{PC} * \text { Vol. }) \\
\mathrm{mg}\end{array}$ & $\begin{array}{l}\text { (HA) } \\
\text { HA titer }\end{array}$ & $\begin{array}{l}\text { THA } \\
\text { AU }\end{array}$ & $\begin{array}{l}\text { Specific activity THA/PC } \\
\text { AS }\end{array}$ & Purification AS stage/AS serum & $\begin{array}{l}\text { Yield } \\
\%\end{array}$ \\
\hline Serum & 20 & 160 & 512 & 10240 & 64 & 1 & 100 \\
\hline PI DIFBL (Fucose-agarose) & 10 & 1.5 & 256 & 2560 & 1706 & 26.6 & \\
\hline PII DIFBL* (Fucose-agarose) & 9.7 & 0.9 & 1024 & 9932 & 11035 & 172 & 0.56 \\
\hline PII DIRBL (Galactose-agarose) & 20 & 0.3 & 64 & 1280 & 4267 & 66.7 & $10\left(0.18^{\#}\right)$ \\
\hline
\end{tabular}

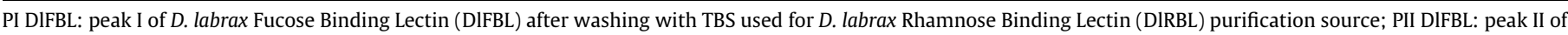

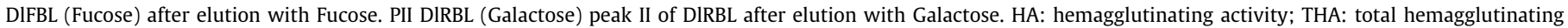
activity; *previously published in Salerno et al., 2009; " referred to serum amount. The purification steps of DIRBL are marked in Bold.

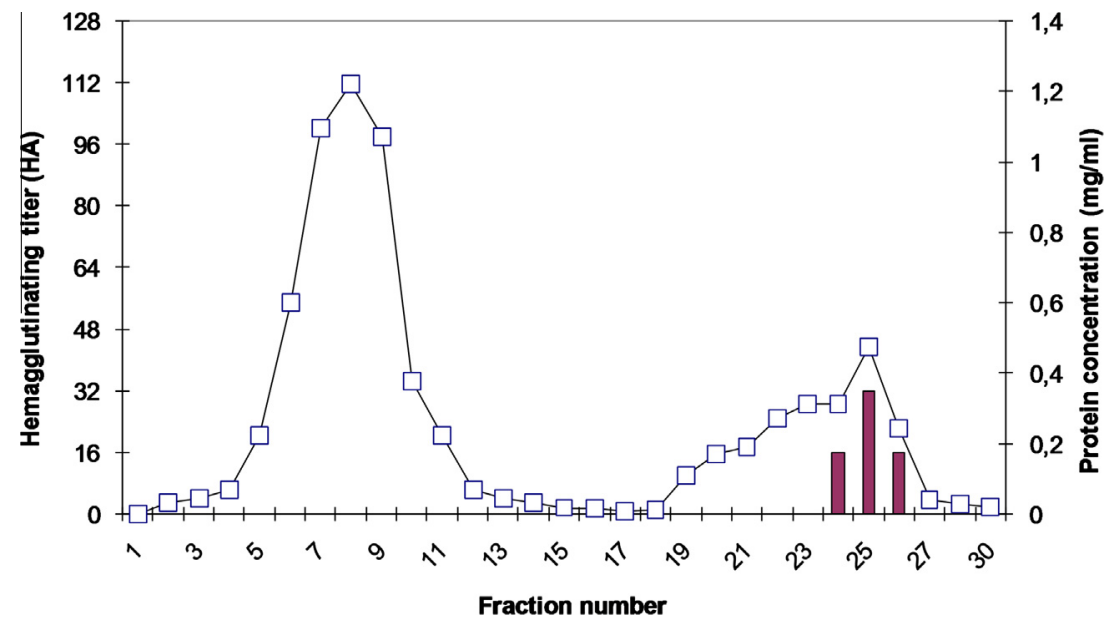

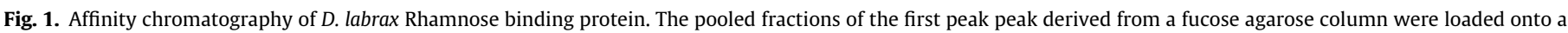

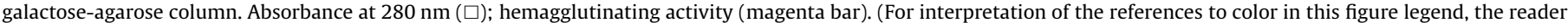
is referred to the web version of this article.)

Table 2

Inhibition of hemagglutination activity of the Dicentrarchus labrax isolated lectin against RE by various carbohydrates.

\begin{tabular}{ll}
\hline Carbohydrate & Minimum inhibitory concentration $(\mathrm{mM})$ \\
\hline Monosaccharides & - \\
D-Glucose & 70.0 \\
D-Galactose & - \\
D-Mannose & - \\
L-Fucose & 4.2 \\
L-Rahmnose & - \\
N-acetyl-D-glucosamine & - \\
N-acetyl-D-galactosamine & \\
Disaccharides & - \\
Lactose & - \\
Lactulose & - \\
Maltose & \\
Polysaccharides & - \\
Mannan &
\end{tabular}

We used rabbit erythrocytes. Inhibitory activity is expressed as the minimum inhibitory concentration that is required to completely inhibit the hemagglutinating activity of a titer. Dashes indicate non inhibitory activity at a concentration of $200 \mathrm{mM}$ for monosaccharides or disaccharides.

\subsection{Phylogenetic analysis, structure and CRD comparison}

BLAST analysis revealed that the DIRBL deduced amino acid sequence presents close homologies with RBLs from invertebrates and fish depending on their CRD organization. In the phylogenetic tree, DIRBL clustered with the other binary teleost RBLs, and homologies with CRDs of vertebrate and invertebrate RBLs, although the teleost binary RBL cluster that includes DIRBL was clearly distinguishable from the invertebrate RBLs. The detailed phylogenetic analysis of the CRDs in RBLs showed highly conserved

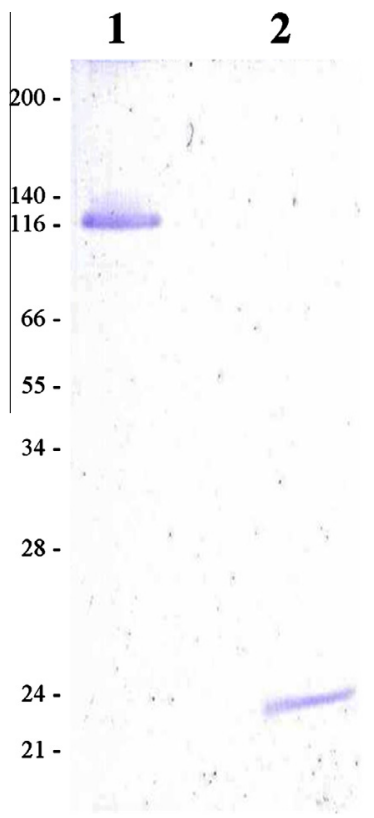

Fig. 2. SDS-PAGE of D. labrax purified lectins. SDS-PAGE analysis of DIRBL $(2.5 \mu \mathrm{g})$ in the absence (lane 1) or presence (lane 2) of reducing agent (NR) (2-mercaptoethanol) on a $12.5 \%$ acrylamide gel stained with Coomassie Blue R-250.

sequences in their N-CRDs or C-CRDs indicating a probably ancient CRDs duplication (Fig. 4B, red and blue box). In contrast, the Nand C-CRD from the echinoderm S. purpuratus and the urochordate C. intestinalis clustered together indicating a closer similarity between their binary $\mathrm{C}$ - and $\mathrm{N}-\mathrm{CRD}$ and a more recent origin of this duplication (Fig. 4B, green box). The homology model of DIRBL 
based on the 0 . mykiss CSL3 RBL structure (40.31\%, of identity $E$ value $0.00 \mathrm{e}-1$ ) showed substantial structural overlap (Fig. 3B).

\subsection{Biochemical and binding properties of DIRBL}

The hemagglutinating activity of the purified DIRBL stored at $20^{\circ} \mathrm{C}$ was stable for more than 2 months. The activity was reduced up to $70 \%$ by incubating the sample for $30 \mathrm{~min}$ at $60^{\circ} \mathrm{C}$, almost abolished after incubation at $90^{\circ} \mathrm{C}$ (Fig. 5A), and reduced in 50$60 \%$ when tested in a medium at $\mathrm{pH}$ lower or higher than 7.0-7.4 (Fig. 5B). The hemagglutinating activity of DIRBL did not appear to require $\mathrm{Ca}^{2+}$ or $\mathrm{Mg}^{2+}$, since $\mathrm{CaCl}_{2}$ or $\mathrm{MgCl}_{2}(5 \mathrm{mM})$ or EDTA or EGTA ( $10 \mathrm{mM}$, either in the presence or absence of $\mathrm{CaCl}_{2}$ or $\mathrm{MgCl}_{2}$ ) added to the eluted fractions (HA ranging from 64 to 512) did not significantly affect the activity. The DIRBL eluted fractions (0.3$0.4 \mathrm{mg} / \mathrm{ml}$ protein) agglutinated both erythrocytes and bacteria (Supplementary Fig. 2, Table 3). Rabbit erythrocytes were aggluti- nated at the highest titers, whereas sheep erythrocytes were not agglutinated at all. With regards the bacteria, the purified DIRBL strongly bound to E. coli $(\mathrm{HT}=128)$, and to lesser extent to A. hidrophyla, S. aureus and V. alginolyticus (Table 3 ).

\subsection{Effect of DIFBL on phagocytic activity of peritoneal macrophages}

The phagocytic rate of peritoneal macrophages increased significantly after $E$. coli were opsonized with $10 \mu \mathrm{g} / \mathrm{ml}$ the isolated DIRBL (from $6.9 \pm 2.9 \%$ to $34.5 \pm 4.2 p<0.001$; 600 cells were counted in three distinct assays) while the phagocytic index increased 2.4-fold (from $1.7 \pm 0.8$ to $4.1 \pm 1.6 p<0.005$ ) (Fig. 6).

\section{Discussion}

Lectins play important roles in the immune responses of invertebrates and vertebrates either by recognizing exposed glycans on
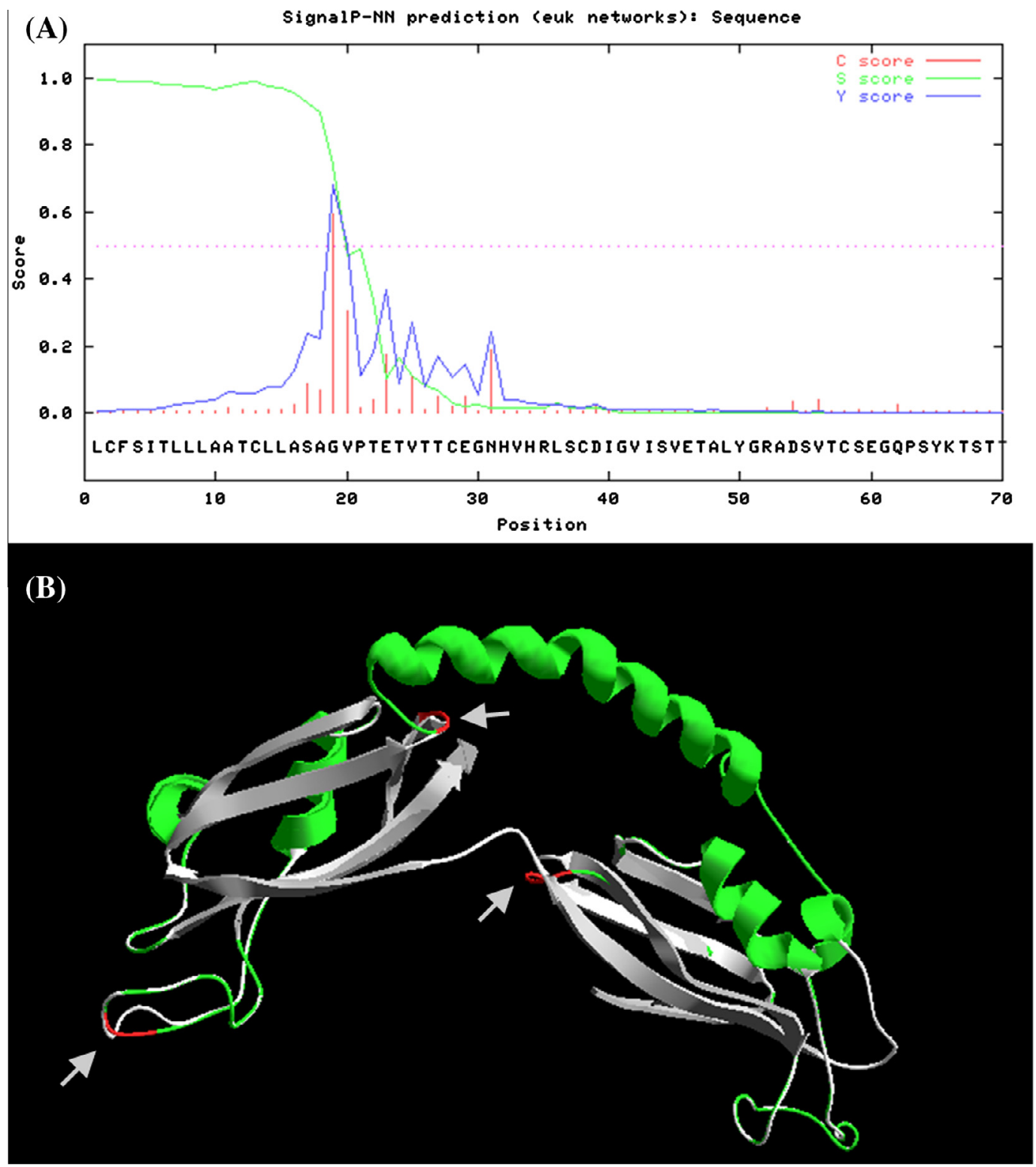

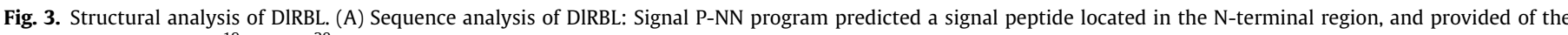

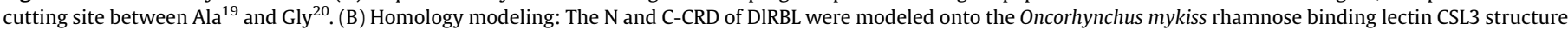

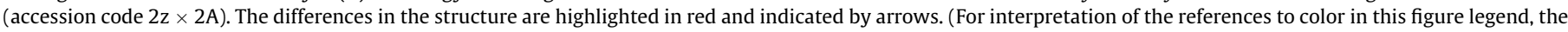
reader is referred to the web version of this article.) 


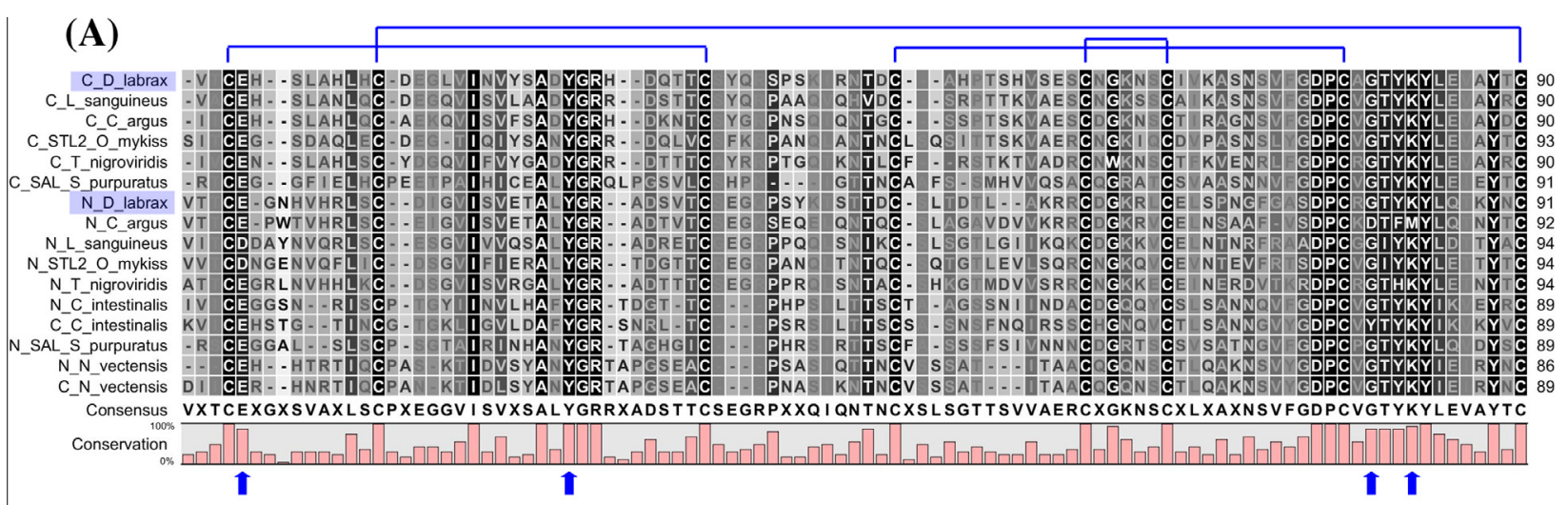

(B)

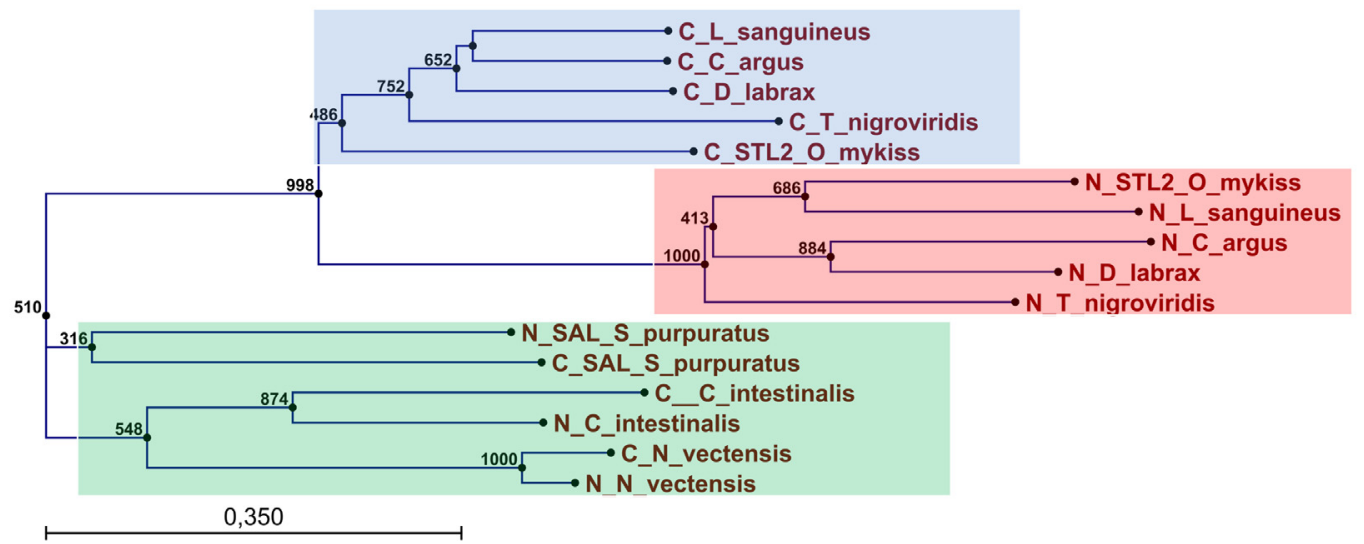

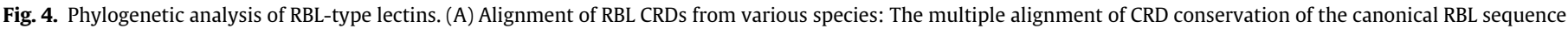

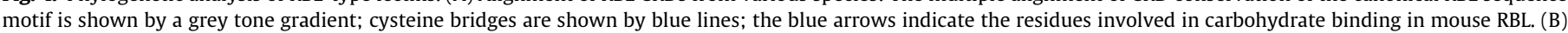

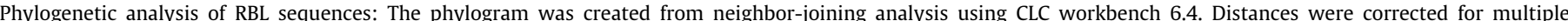

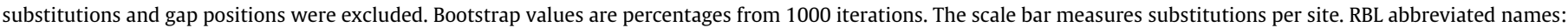

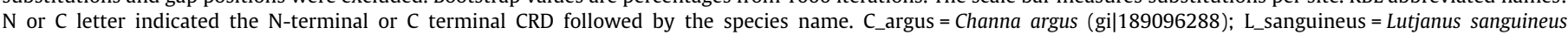

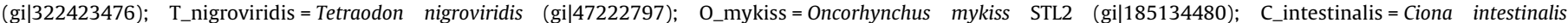

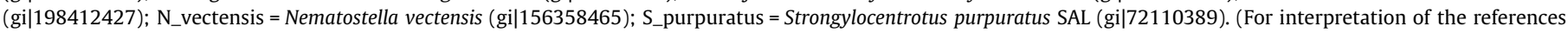
to color in this figure legend, the reader is referred to the web version of this article.)

potential pathogens or by their immunoregulatory roles through the binding to carbohydrates on the surfaces of immunocompetent cells (Kuhlman et al., 1989; Cooper et al., 1994; Tino and Wright 1996; Matsushita et al., 1996; Vasta and Ahmed, 2008; Vasta, 2009). It has been proposed that the RBLs are involved in the regulation of carbohydrate metabolism, control of fertilization and cytotoxicity (Tateno et al., 2002a; Watanabe et al., 2009). In addition, an enhancing effect on cell proliferation has been reported for RBL of human dermal fibroblasts (Faury et al., 2008). Immune challenge in fish upregulates RBLs expression, leading to increased opsonization and phagocytosis of the microbes, and inducing the synthesis and release of pro-inflammatory cytokines (Lam and Ng 2002; Tateno et al., 2002a; Terada et al., 2007; Jia et al., 2009; Watanabe et al., 2009; Ogawa et al., 2011).

In a previous report we characterized a $34 \mathrm{kDa}$ fucose-binding lectin from D. labrax serum (DIFBL) isolated through Sepharose 6BCL affinity chromatography (Cammarata et al., 2001). In subsequent studies (Cammarata et al., 2007, 2012; Salerno et al., 2009) we established that DIFBL and SauFBL, a lectin from the gilt head sea bream (Sparus aurata) of similar binding properties, were both members of the F-type lectin family,and are also present in eggs (Parisi et al., 2010). During affinity chromatography of D. labrax serum on L-fucose-agarose a protein peak with hemagglutinating activity that was susceptible to inhibition by L-rhamnose and D-galactose but not by L-fucose was identified, suggesting that this was a serum lectin distinct from DIFBL. In the present study we optimized the purification procedure for this lectin, which we desig-

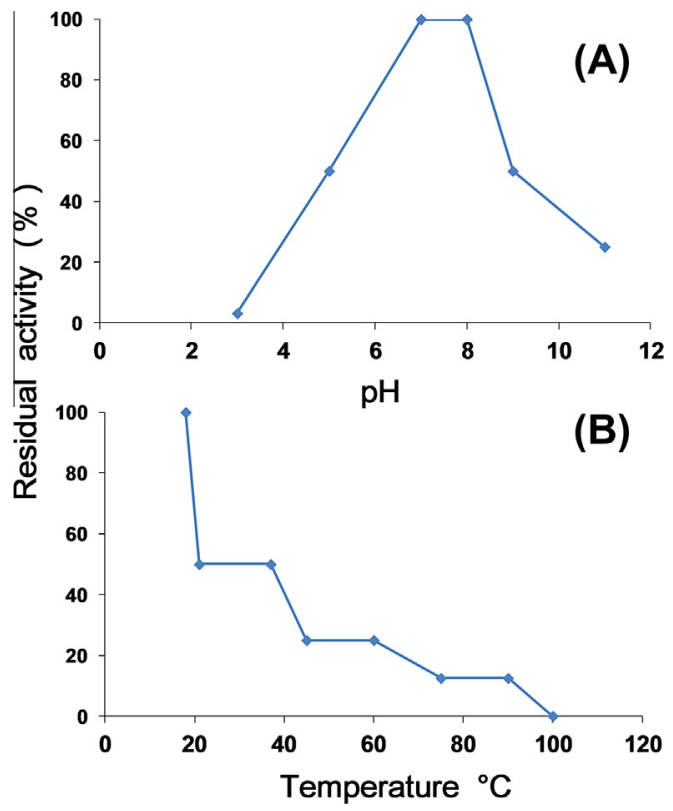

Fig. 5. Thermal stability and optimal pH range of DIRBL binding activity. DIRBL was incubated at various temperatures for $30 \mathrm{~min}$ then cooled on ice for $10 \mathrm{~min}$. The residual hemagglutination activity was tested at room temperature. The hemagglutination activity of an untreated sample, tested at room temperature, represented $100 \%$ activity sample was incubated with buffer ranging from $\mathrm{pH} 3-11$. The titer value obtained at $\mathrm{pH} 8.0$ represented $100 \%$ activity. 
Table 3

Hemagglutinating (titer ${ }^{-1}$ ) against various erythrocyte types and bacteria by a Rhamnose (DIRBL) and Fucose ${ }^{a}$ (DIFBL) binding lectins from Dicentrarchus labrax activity of purified lectin $(50 \mu \mathrm{g} / \mathrm{ml})$.

\begin{tabular}{lll}
\hline & \multicolumn{2}{l}{ Agglutination activity $^{\mathrm{c}}$} \\
\cline { 2 - 3 } & Purified RBL & Purified FBL \\
\hline Erythrocytes $^{\mathrm{b}}$ & & \\
Human A & 16 & 64 \\
Human B & 16 & 2 \\
Human AB & 16 & 64 \\
Human 0 & 16 & $256-512$ \\
Rabbit & $32-128$ & \\
Bacteria & & - \\
E. coli & 128 & - \\
V. alginolyticus & 8 & - \\
A. hidrophyla & 16 & - \\
S. aureus & 16 & \\
\hline
\end{tabular}

a Salerno et al. (2009).

b Erythrocytes were collected in Alsever solution and washed five times by centrifuging at $800 \mathrm{~g}$ for $5 \mathrm{~min}$ in Tris-buffer saline $(\mathrm{pH} 7.5)$. The packed cells were suspended in TBS to give a $1 \%(\mathrm{~V} / \mathrm{V})$ suspension of native erythrocytes and used to test hemagglutination activity.

c Hemagglutination activity was expressed as a titer, the reciprocal of the highest twofold dilution exhibiting hemagglutination (HA). Dashes indicate no activity. The agglutinating assays were performed in 96-well V-bottomed microtiter plates. Samples $(25 \mathrm{~mL})$ were serially diluted twofold in TBS, and an equal volume of erythrocyte suspension was added to each well. The plates were shaken gently and then incubated at $37{ }^{\circ} \mathrm{C}$ for $1 \mathrm{~h}$ (bacteria at room temperature for $24 \mathrm{~h}$ ). The data presented are from one representative experiment that was repeated three times.

nated DIRBL, and characterized its molecular, structural, and biological properties.

For the purification of DIRBL we developed a two-step affinity chromatography procedure in which the pooled active fractions from the first peak of the L-fucose-agarose column were loaded onto a galactose-agarose affinity column, and eluted with $50 \mathrm{mM}$ galactose. Based on the electrophoretic mobility in polyacrylamide gels, the purified DIRBL is constituted by $24 \mathrm{kDa}$ subunits. Cloning of full length DIRBL transcript revealed that it consists of an open reading frame encoding 212 aminoacid residues including 18 residue signal sequence at the $\mathrm{N}$-terminal. This was fully supported by a transcript (Accession number: NP_001117668, BAA92256; Sarropoulou et al., 2009) identified in a D. labrax EST library. The deduced size of $24.1 \mathrm{kDa}$ for the mature protein is in good agreement with subunit size of the isolated lectin $(24 \mathrm{kDa})$.
Comparative sequence analysis revealed that DIRBL is a binary tandem domain RBL-type lectin with the $\mathrm{N}$ - and C-CRDs connected by a six-amino acid peptide linker.

The RBL CRD can be characterized by highly conserved 4 disulfide bridges at homologous positions as well as the conserved motif.

BLAST analysis of DIRBL disclosed sequence homologies with multiple RBLs from invertebrate and vertebrate species RBL CRDs. In the phylogenetic tree, DIRBL included in a cluster of teleost binary RBL-type lectins, clearly distinguishable from those invertebrate RBL with a single CRD. Both N-CRD and C-CRD from fish showed highly conserved sequences indicating a probably ancient origin of CRDs duplication. The N- and C-CRDs from N. vectensis, $S$. purpuratus and $C$. intestinalis clustered together, indicating a more recent CRD duplication.

Electrophoresis of DIRBL in polyacrylamide gels under nonreducing conditions indicated that the $24 \mathrm{kDa}$ subunits are organized as a $100 \mathrm{kDa}$ tetramer. The presence of two CRDs in each polypeptide subunit, and therefore, the physiological DIRBL tetramer displays 8 CRDs, suggesting that this multivalency is responsible for the observed agglutinating properties for erythrocytes and bacteria. A similar subunit size and quaternary organization has been described for other teleost RBLs such as the CSL1 isolated from chum salmon eggs, that is also organized as a homotetramer, and therefore displays 8 CRDs (Watanabe et al., 2009). In contrast, the RBL subunits of CSL2 and CSL3, isolated from the same species, can also form homooctadecamers and homodimers, respectively, and therefore display 36 and 4 CRDs.

DIRBL actively agglutinates rabbit and human erythrocytes but does not require divalent cations for binding to the carbohydrate ligands, as all cations and chelators tested had no effect on the DIRBL hemagglutinating activity. Similar observations have been made in other fish RBLs, including the steelhead trout (O. mykiss) egg lectin, grass carp (Ctenopharyngodon idellus) roe lectin, rudd (Scardinius erythropthalmus) roe lectin, and olive rainbow smelt (Osmerus eperlanus mordax) roe lectin (Lam and Ng 2002; Hosono et al., 1993).

In addition to the hemagglutinating activity, DIRBL bind both Gram-negative and Gram-positive bacteria. The ability to recognize and bind lipopolysaccharides and lipoteichoic acid and agglutinate both Gram-positive and Gram-negative bacteria has been described in trout RBLs, suggesting an antibacterial activity (Tateno et al., 2002a). We show clearly the presence of DIRBL in the serum. Other
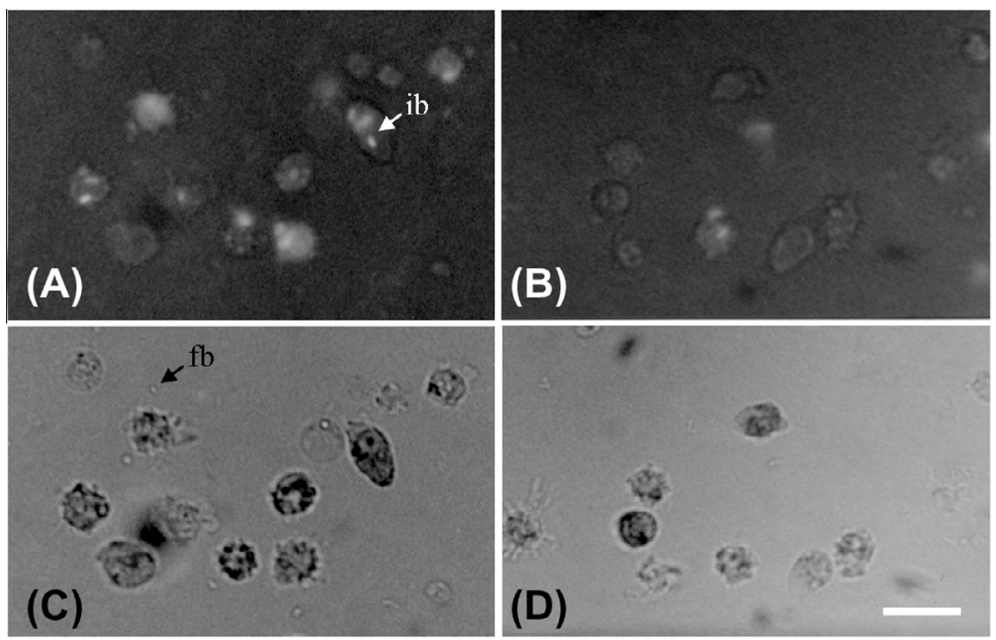

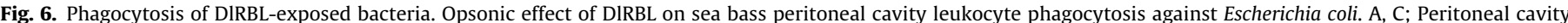

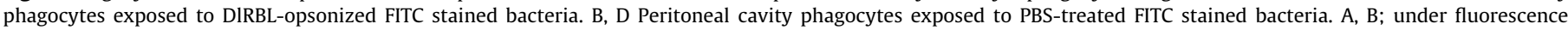
microscope. C, D; under light microscope. IB: ingested bacteria; FB: free bacteria. Bar $20 \mu \mathrm{m}$. 
authors have demonstrated thet RBLs are mainly localized in the tissues related to the immune system, such as mucous cells of gills, goblet cells of intestine, spleen, thrombocytes, lymphocytes, monocytes and neutrophils (Watanabe et al., 2008; Tateno et al., 2002c).

In addition, RBLs have also been found in the cortex of teleost eggs as well as in the skin mucus, further confirming their protective role. A putative natural ligand of fish RBL is the glycosphingolipid globotriasylceramide (Gb3), abundant in membrane lipid rafts (Watanabe et al., 2009; Ogawa et al., 2011).

The exposure of formalin-killed E. coli to DIRBL enhanced their phagocytosis by peritoneal macrophages. The opsonic activity of DIRBL, together with its capacity of bacterial agglutination observed support the hypothesis that the plasma DIRBL mediates not only agglutination and immobilization of potentially pathogenic microorganisms, but also promotes their phagocytosis and clearance from circulation, thereby playing a key role in host defense against infectious challenge.

Finally, our results confirmed a model for innate immunity in fish proposed by Watanabe et al. (2009) in which RBLs recognize various kinds of pathogens in inflammatory site thought the blood circulation and enhance their phagocytosis by binding on the leukocyte surface.

\section{Acknowledgements}

We are grateful to Mario Guarcello for expert fish maintenance. This work was supported by grants from MIUR, and MC RITMARE project (CNR and CONISMA) and by grant 5R01GM070589-06 from the National Institutes of Health to GRV.

\section{Appendix A. Supplementary data}

Supplementary data associated with this article can be found, in the online version, at http://dx.doi.org/10.1016/j.dci.2014.01.019.

\section{References}

Arason, G.J., 1996. Lectins as defence in vertebrates and invertebrates. Fish Shellfish Immunol. 6, 277-289.

Arnold, K., Bordoli, L., Kopp, J., Schwede, T., 2006. The SWISS-MODEL Workspace: a web-based environment for protein structure homology modelling. Bioinformatics 22, 195-201.

Bianchet, M.A., Odom, E.W., Vasta, G.R., Amzel, L.M., 2010. Structure and specificity of a binary tandem domain F-lectin from striped bass (Morone saxatilis). J. Mol. Biol. 401, 239-252.

Bradford, M.M., 1976. A rapid and sensitive method for the quantitation of microgram quantitites of protein utilizing the principle of protein- dye binding. Anal. Biochem. 72, 248-254.

Cammarata, M., Benenati, G., Odom, E., Salerno, G., Vizzini, A., Vasta, G.R., Parrinello, N., 2007. Isolation and characterization of a fish F-type lectin from gilt head bream (Sparus aurata) serum. Biochim. Biophys. Acta 1770, 150-155.

Cammarata, M., Salerno, G., Parisi, M.G., Benenati, G., Vizzini, A., Vasta, G.R., Parrinello, N., 2012. Primary structure and opsonic activity of an F-lectin from serum of the gilt head bream Sparus aurata (Pisces, Sparidae). Ital. J. Zool. 79, $34-43$.

Cammarata, M., Vazzana, M., Chinnici, C., Parrinello, N., 2001. A serum fucolectin isolated and characterized from sea bass Dicentrarchus labrax. Biochim. Biophys. Acta 1528, 196-202.

Cooper, D., Butcher, C.M., Berndt, M.C., Vadas, M.A., 1994. P-selectin interacts with a beta 2-integrin to enhance phagocytosis. J. Immunol. 153, 3199-3209.

Faury, G., Ruszova, E., Molinari, J., Mariko, B., Raveaud, S., Velebny, V., Robert, L. 2008. The alpha-t-Rhamnose recognizing lectin site of human dermal fibroblasts functions as a signal transducer: modulation of $\mathrm{Ca}^{2+}$ fluxes and gene expression. Biochim. Biophys. Acta 1780, 1388-1394.

Fujita, T., Matsushita, M., Endo, Y., 2004. The lectin-complement pathway-its role in innate immunity and evolution. Immunol. Rev. 198, 185-202.

Gabius, H.J., 1997. Animal lectins. Eur. J. Biochem. 243, 543-576.

Guex, N., Peitsch, M.C., 1997. SWISS-MODEL and the Swiss-PdbViewer: an environment for comparative protein modelling. Electrophoresis 18, $2714-$ 2723.

Hosono, M., Kawauchi, H., Nitta, K., Takatanagi, Y., Shiokawa, H., Mineki, R., et al., 1993. Three rhamnose-binding lectins from Osmerus eperlanus mordax (Olive rainbow smelt) roe. Biol. Pharm. Bull. 16, 239-243.
Jia, H., Liu, Y., Yan, W., Jia, J., 2009. PP4 and PP2A regulate Hedgehog signaling by controlling Smo and Ci phosphorylation. Development 136, 307-316.

Jimbo, M., Usui, R., Sakai, R., Muramoto, K.H., 2007. Purification, cloning and characterization of egg lectins from the teleost Tribolodon brandti. Comp. Biochem. Physiol. B: Biochem. Mol. Biol. 1, 17331-17772.

Kaltner, H., Stierstorfer, B., 1998. Animal lectins as cell adhesion molecules. Acta Anat. 161, 162-179.

Kilpatrick, D.C., 2002. Animal lectins: a historical introduction and overview. Biochim. Biophys. Acta 1572, 187-197.

Kuhlman, M., Joiner, K., Ezekowitz, A.B., 1989. The human mannose-binding protein functions as an opsonin. J. Exp. Med. 169, 1733-1745.

Laemmli, U.K., 1970. Cleavage of structural proteins during the assembly of the head of bacteriophage T4. Nature 227, 680-685.

Lam, Y.W., Ng, T.B., 2002. Purification and characterization of a rhamnose-binding lectin with immuno enhancing activity from grass carp (Ctenopharyngodon idellus) ovaries. Protein Expr. Purif. 26, 378-385.

Loris, R., 2002. Principles of structures of animal and plant lectins. Biochim. Biophys. Acta $1572,198-208$.

Matsushita, M., Endo, Y., Taira, S., Sato, Y., Fujita, T., Ichikawa, N., Nakata, M., Mizuochi, T.A., 1996. Novel human serum lectin with collagen- and fibrinogen like domains that functions as an opsonin. J. Biol. Chem. 271, 2448-2454.

Odom, E., Vasta, G.R., 2006. Characterization of a Binary Tandem Domain F-type Lectin from Striped Bass (Morone saxatilis). J. Biol. Chem. 281, 1698-1713.

Ogawa, T., Watanabe, M., Naganuma, T., Muramoto, K., 2011. Diversified carbohydrate-binding lectins from marine resources. J. Amino Acids, 838914. http://dx.doi.org/10.4061/2011/838914.

Parisi, M.G., Cammarata, M., Benenati, G., Salerno, G., Mangano, V., Vizzini, A., Parrinello, N., 2010. A serum fucose-binding lectin (DlFBL) from adult Dicentrarchus labrax is expressed in larva and juvenile tissues and contained in eggs. Cell Tissue Res. 341, 279-288.

Salerno, G., Parisi, M.G., Parrinello, D., Benenati, G., Vizzini, A., Vazzana, M., Vasta, G.R., Cammarata, M., 2009. F-type lectin from the sea bass (Dicentrarchus labrax): purification, cDNA cloning, tissue expression and localization, and opsonic activity. Fish Shellfish Immunol. 27, 143-153.

Sarropoulou, E., Sepulcre, P., Poisa-Beiro, L., Mulero, V., Meseguer, J., Figueras, A., Novoa, B., Terzoglou, V., Reinhardt, R., Magoulas, A., Kotoulas, G., 2009. Profiling of infection specific mRNA transcripts of the European seabass Dicentrarchus labrax. BMC Genomics 10, 157. http://dx.doi.org/10.1186/14712164-10-157.

Schwede, T., Kopp, J., Guex, N., Peitsch, M.C., 2003. SWISS-MODEL: an automated protein homology-modeling server. Nucleic Acids Res. 31, 3381-3385.

Sharon, N., Lis, H., 2004. History of lectins: from hemagglutinins to biological recognition molecules. Glycobiology 14, 53-62.

Shiina, N., Tateno, H., Ogawa, T., Muramoto, K., Saneyoshi, M., Kamiya, H., 2002. Isolation and characterization of L-rhamnose-binding lectins from chum salmon (Oncorhychus keta) eggs. Fish. Sci. 68, 1352-1366.

Tateno, H., Yamaguchi, T., Ogawa, T., Muramoto, K., Watanabe, T., Kamiya, H., et al., 2002a. Immunohistochemical lacalization of rhamnose-binding lectins in the steelheadtrout (Oncorhychus mykiss). Dev. Comp. Immunol. 26, 543-550.

Tateno, H., Ogawa, T., Muramoto, K., Kamiya, H., Saneyoshi, M., 2002b. Rhamnosebinding lectins from eggs from steelhead trout (Oncorhynchus mykiss) Eggs recognize bacterial lipopolysaccharides and lipoteichoic acid. Biosci. Biotechnol. Biochem. 66, 604-612.

Tateno, H., Shibata, Y., Nagahama, Y., Hirai, T., Saneyoshi, M., Ogawa, T., et al., 2002c. Tissues pecific expression of rhamnose-binding lectins in the steelhead trout (Oncorhynchus mykiss). Biosci. Biotechnol. Biochem. 66, 1427-1430.

Tateno, H., Saneyoshi, A., Ogawa, T., Muramoto, K., Kamiya, H., Saneyoshi, M., 1998. Isolation and characterization of rhamnose-binding lectins from eggs of steelhead trout (Oncorhynchus mykiss) homologous to low density lipoprotein receptor superfamily. J. Biol. Chem. 273, 19190-19197.

Terada, T., Watanabe, Y., Tateno, H., Naganuma, T., Ogawa, T. Muramoto, K, et al. 2007. Structural characterization of a rhamnose-binding glycoprotein (lectin) from Spanish mackerel (Scomberomorous niphonius) eggs. Biochim. Biophys. Acta 1770, 617-629.

Tino, M.J., Wright, J.R., 1996. Surfactant protein a stimulates phagocytosis of specific pulmonary pathogens by alveolar macrophages. Am. J. Physiol. 270, 677.

Turner, M.W., 1996. Mannose-binding lectin: the pluripotent molecule of the innate immune system. Immunol. Today 17, 532-540.

Vasta, G.R., Ahmed, H., 2008. Animal Lectins: A Functional View. CRC Press.

Vasta, G.R., Nita-Lazar, M., Giomarelli, B., Ahmed, H., Du, S., Cammarata, M., Parrinello, N., Bianchet, M.A., Amzel, L.M., 2011. Structural and functional diversity of the lectin repertoire in fish: relevance to innate and adaptive immunity. Dev. Comp. Immunol. 35, 1388-1399.

Vasta, G.R., Ahmed, H., Bianchet, M.A., Fernández-Robledo, J.A. Amzel, L.M. 2012. Diversity in recognition of glycans by F-type lectins and galectins: molecular, structural, and biophysical aspects. Ann. N.Y. Acad. Sci. 1253, 14-26.

Vasta, G.R., Ahmed, H., Fink, N.E., Elola, M.T., Marsh, A.G., Snowden, A., Odom, E.W., 1994. Animal lectins as self/non-self recognition molecules. Biochemical and genetic approaches to understanding their biological roles and evolution. Ann. N.Y. Acad. Sci. 712, 55-73.

Vasta, G.R., 2009. Roles of galectins in infection. Nat. Rev. Microbiol. 7, 424-438.

Vasta, G.R., Ahmed, H., Odom, E.W., 2004. Structural and functional diversity of lectin repertoires in invertebrates, protochordates and ectothermic vertebrates. Curr. Opin. Struct. Biol. 11, 53-62. 
Watanabe, Y., Shiina, N., Shinozaki, F., Yokoyama, H., Kominami, J., NakamuraTsuruta, S., et al., 2008. Isolation and characterization of rhamnose-binding lectin, which binds to microsporidian Glugea plecoglossi, from ayu (Pleacoglossus altivelis) eggs. Dev. Comp. Immunol. 32, 487-499.
Watanabe, Y., Tateno, H., Nakamura-Tsuruta, S., Kominami, J., Hirabayashi, J., Nakamura, O., Watanabe, T., Kamiya, H., Naganuma, T., Ogawa, T., Naudé, R.J. Muramoto, K., 2009. The function of rhamnose-binding lectin in innate immunity by restricted binding to Gb3. Dev. Comp. Immunol. 33, 187-197. 